\title{
Antibiotics effect on salmonella spp .isolated from young chicks in chicken fields
}

\author{
Hameedh Hamza Al-Hababy \\ (Microbiology department, Veterinary medicine college/Al-Qasim green University, Iraq)
}

\begin{abstract}
The aim of the present study was the isolation and diagnosis of the bacteria that cause bacillary white diarrhea from young chicks, identification the present percentage, and establishment the antibiotic effect on bacteria. Bacillary white diarrhea disease is a major health problem as the causative agent Salmonella pullorum has developed resistance to many antimicrobial agents. We studied 88samples feces collect from chicken in the chicken felid in Hilla city (Babylon province.).These samples were cultured on selective and differential media; biochemical tests and antimicrobial effect on the types of these bacteria was studied. Antimicrobial susceptibility testing was done by disc diffusion method. The results showed that, 68 isolate were S. pullorum and 20 isolate were S. enteritidis. Regarding Antibiotics sensitivity test, S. pullorum and S.entreitidis were highly sensitive to ciprofloxacin, (100\%), (90\%) respectively, followed by amikacin (88\%) for S. pullorum and (80\%) for S.entreitidis. While erythromycin, enrofloxacin and chloramphenicol were not effective against tested isolates. The findings of the present study revealed the presence of multidrug resistant Salmonella species in young chicks from chicken fields in Hilla city.
\end{abstract}

Keywords: Antimicrobial susceptibility, Salmonella species, Bacillary white diarrhea disease, Young Chicks.

\section{Introduction}

Salmonella infection is one of the most important global poultry diseases which are caused by different Salmonella species $(1,2)$. More than 2,500 serotypes have been described mostly under the species $(3,4)$. Salmonellosis, especially the one that manifests as Pullorum disease, is one of the commonest diseases of local poultry, which causes severe economic loss to the industry. S.Pullorum and S.enteriditis are both normally reported to attack poultry $(5,6)$. Few diseases are more devastating to poultry producers than pullorum. In 1899 , Salmonella pullorum was the first identified bacteria that causes heavy losses in chicks and poults and decreases the productivity of adult birds.

An infection that begins with a single bird can spread quickly through a flock, causing mortality as high as $80 \%$ or more $(7,8)$. Pullorum disease is usually transmitted in the egg hen, but may also be spread through breathing or consuming contaminated dust, down, droppings or broken eggs, mating with an infected male. Infections with Salmonella pullorum can result in acute systemic disease and a high incidence of mortality in young poultry. Vertical transmission of $S$. pullorum from infected parent flocks, magnified by horizontal transmission in the hatcher, can cause economically devastating losses among chicks or poults $(9,10)$. The use of antimicrobials in veterinary medicine as food animal growth promoting agents during the past decade has created enormous pressure for selection of antimicrobial resistance among bacterial pathogens worldwide $(11,12,13)$. Nowadays, there is increasing concern about the development of multidrug resistance in bacteria causing zoonosis and having an important animal reservoir, such as Salmonella strains $(14,15)$. The aim of the present study was the isolation and diagnosis of the bacteria that cause bacillary white diarrhea from young chicks, identification the present percentage, and establishment the antibiotic effect on bacteria.

\section{Material And Methods}

1. Sample collection:

Fecal samples were collected from chicken fields in Hilla city (during a period from February to August 2013).A total of 88 specimens of Salmonella were collected, all the specimens were isolated and identified culturing and biochemically using standard procedures. Subcultures were done on nutrient agar, MacConkey agar, Salmonella-Shigella agar(SS) and Xylose lysine deoxycholate agar (XLD) and incubated at $37^{\circ} \mathrm{C}$ for 18 to $24 \mathrm{hr}$. All the isolates were stored in brain heart infusion broth with $15 \%$ glycerol at $-20^{\circ} \mathrm{C}$ until further use $(10,16$, and 17$)$.

\section{Antibiotic susceptibility testing:}

Antimicrobial susceptibility testing of the isolates to various routinely used antibiotics was determined by disc diffusion technique on Muller Hinton agar using commercially available discs following CLSI guidelines (2010). The panel of antimicrobials was show in Table (1).Sterile swab was used to inoculate the suspension by streaking on the prepared and dried Mueller Hinton agar plate evenly. It was then allowed to stay 
for 3-5 minutes. Sterile forceps was used to place the antimicrobial discs on the inoculated plates. Within 30 minutes after applying the disc, the plate was incubated at $37^{\circ} \mathrm{C}$ for $18-24$ hours. By using Meter rule on the underside of plate, the diameter of each zone of inhibition was measured in millimeter. Zone diameter for isolate was compared with CLSI Published Limits; interpretative chart was then used to interpret the zone sizes of inhibition. Result was recorded as susceptible, intermediate susceptible, or resistant based on the Zones sizes of each antimicrobial disc used. The results then interpreted according to CLSI documentation (18).

Table (1): Interpretive standards for disc diffusion susceptibility testing of salmonella (18).

\begin{tabular}{|c||c|c|c|c|c|}
\hline \multirow{2}{*}{ Antibiotic disc } & \multirow{2}{*}{ Symbol } & \multirow{2}{*}{ Disc concentration } & \multicolumn{2}{|c|}{ Diameter of zone of inhibition (mm) } \\
\cline { 4 - 6 } & & & Susceptible & intermediate & Resistant \\
\hline Amikacin & AK & $30 \mu \mathrm{g}$ & $\geq 17$ & $15 \sim 16$ & $\leq 14$ \\
\hline \hline Chloramphenicol & $\mathrm{C}$ & $30 \mu \mathrm{g}$ & $\geq 18$ & $13 \sim 17$ & $\leq 12$ \\
\hline \hline Rifampin & RA & $5 \mu \mathrm{g}$ & $>20$ & $17 \sim 19$ & $<16$ \\
\hline \hline Ciprofloxacin & CIP & $5 \mu \mathrm{g}$ & $\geq 21$ & $16 \sim 20$ & $\leq 15$ \\
\hline \hline Enrofloxacin & ENR & $5 \mu \mathrm{g}$ & $\geq 20$ & $17 \sim 19$ & $\leq 16$ \\
\hline \hline Gentamicin & CN & $10 \mu \mathrm{g}$ & $\geq 15$ & $13 \sim 14$ & $\leq 12$ \\
\hline \hline Erythromycin & $\mathrm{E}$ & $15 \mu \mathrm{g}$ & $\geq 23$ & $14 \sim 22$ & $\leq 13$ \\
\hline
\end{tabular}

\section{Isolation of bacteria :}

III. Results And Discussion

The results were shown in Fig. (1) indicated that growth was observed in 68(77.27\%) Salmonella pullorum, while 20(22.73\%) Salmonella enteritidis from88 total specimens.

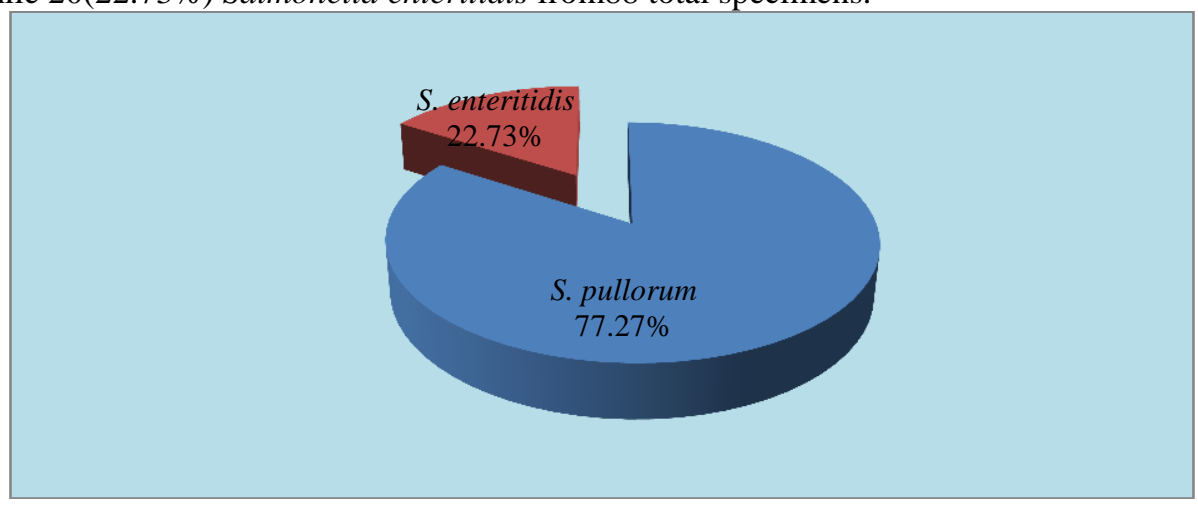

Figure (1): Percentage of isolations.

\section{Laboratory identification of salmonella spp.:}

In this study, salmonella spp. isolates were identified by investigation of colonial morphology on MacConkey agar in which the colonies appeared smooth, colorless and gram negative non-sporogenic, rod shape. While growth on Xylose lysine deoxycholate agar (XLD) and Salmonella - shigella agar (SS)as small red translucent colonies without black color in center of colonies and motile as Salmonella pullorum, while Salmonella enteritidis has been non-motile and growth on XLD and SS agar may have a central black spot due to $\mathrm{H}_{2} \mathrm{~S}$ production $(19,20)$.According to the age (from 1 to 12 days), chick samples distribution showed high infection rate with Salmonella pullorum in small ages chicks, while Salmonella enteritidis infection was high in large chicks as shown in Table (2).

Table (2): The distribution of isolates is according to the age of chick.

\begin{tabular}{|c|c|c|c|c|}
\hline \multirow{3}{*}{ No. } & \multicolumn{4}{|c|}{ Chick samples } \\
\hline & \multirow{2}{*}{ Age (days) } & \multicolumn{2}{|c|}{ Isolate } & \multirow{2}{*}{ Total (\%) } \\
\hline & & S. Pullorum & S. enteritidis & \\
\hline$\overline{1}$ & 5 & 36 & $\overline{0}$ & $36(41)$ \\
\hline 2 & 7 & 24 & 8 & $32(36.3)$ \\
\hline 3 & 12 & 8 & 12 & $20(22.7)$ \\
\hline \multicolumn{2}{|c|}{ Total } & 68 & 20 & $88(100)$ \\
\hline
\end{tabular}


Many studies have been conducted by many researchers in different parts of the world establishing the significance of pullorum disease in chicks. The above two species of Salmonella spp. were encountered in this study. Among the Salmonella spp. isolated S. pullorum was predominant, followed by S.enteritidis. In the present study, specific enriched media and biochemical tests were used for the isolation and identification of Salmonella spp. which was also used by a number of researchers $(2,8,20)$. The colony characteristics of Salmonella spp. exhibited colorless, smooth, transparent on MacConkey agar; black or colorless on SS agar and translucent, opaque, smooth colonies on nutrient agar were similar to the findings of other authors $(1,10,21)$. In indole test, all the test isolates $(\mathrm{n}=88)$ did not develop any red color which indicated the Salmonella isolates were negative to indole test (22). In case of reaction in TSI agar slant, $77.27 \%$ of the isolates $(n=68)$ produced red slant, yellow but without the production of $\mathrm{H}_{2} \mathrm{~S}$ and no gas, while $22.73 \%$ isolates $(\mathrm{n}=20)$ were associated with the production of $\mathrm{H}_{2} \mathrm{~S}$ which strongly supported the observations of others $(8,10)$.

\section{The sensitivity of salmonella spp to the antibiotic by using disk diffusion test:}

In this test, 88 samples were included and the antimicrobial susceptibility patterns of Salmonella spp. against various antibiotics were studied. Out of 68 Salmonella pullorum isolates, 68(100\%) were resistant to erythromycin, enrofloxacin and chloramphenicol. On the other hand, $68(100 \%)$ were susceptible to ciprofoloxacin, 60(88\%) were susceptible to amikacin, 52(76\%) were susceptible to rifampin and $45(66 \%)$ were susceptible to gentamicin as shown in Fig. (2).

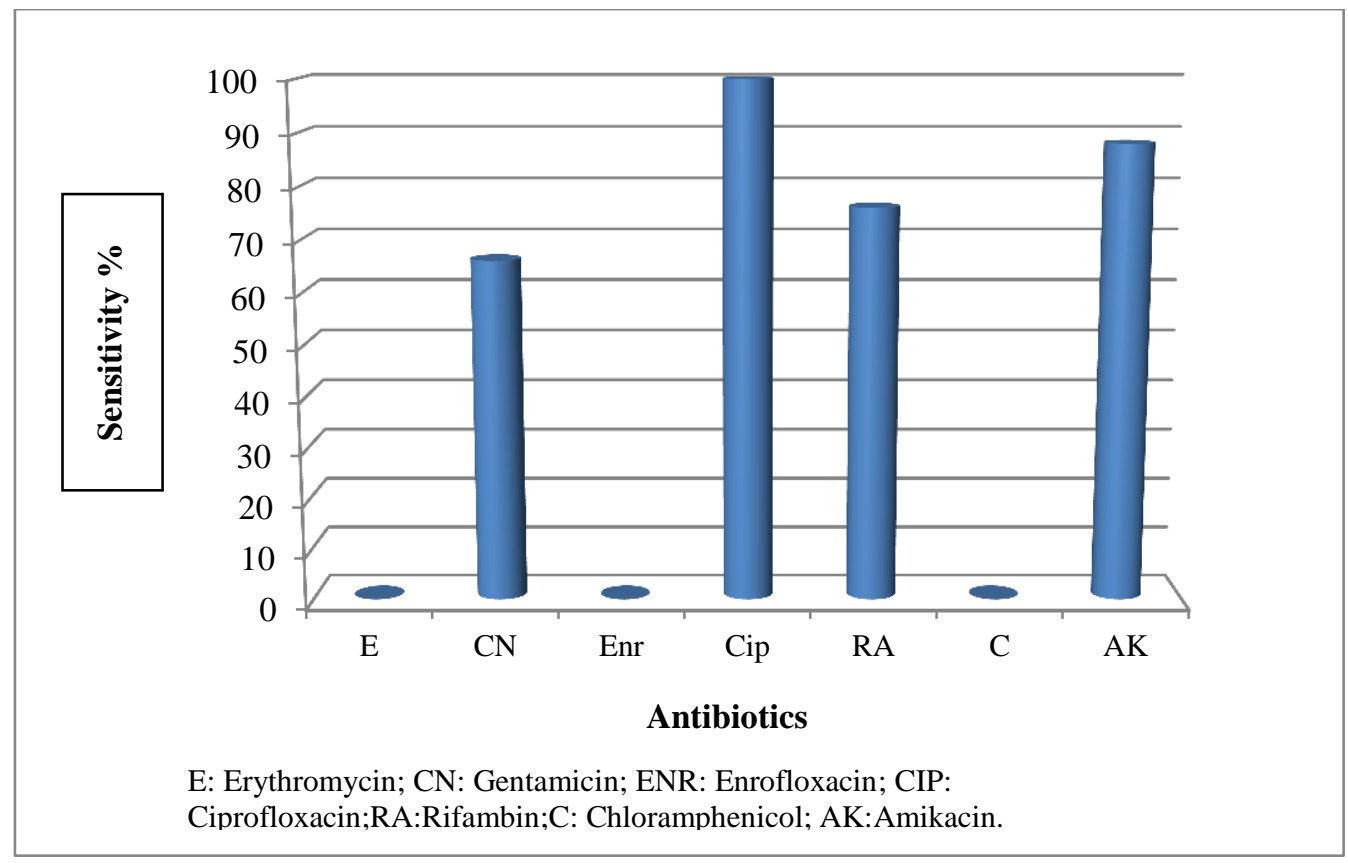

Figure (2): Sensitivity rate of $S$. pullorum to different antibiotics.

Out of 20 Salmonella entreitid is isolates, 20(100\%) were resistant to erythromycin, enrofloxacin, chloramphenicol and gentamicin. Furthermore, 18 (90\%) were susceptible to ciprofloxacin, and 16(80\%) were susceptible to amikacin Fig. (3).In antimicrobial susceptibility testing, out of 68 Salmonella pullorum isolates, $68(100 \%)$ were resistant to erythromycin, enrofloxacin and chloramphenicol. Out of 20 S.entreitidis isolate, $20(100 \%)$ were resistant to erythromycin, enrofloxacin, chloromphenchol, and gentamicin. The antibiotic resistance of Salmonella strains of avian origin was attributed to chromosomal mutation, gene transfer mechanisms like conjugation, transduction and transformation (12, 23, 24, 25 and 26). Additionally, out of 68 Salmonella pullorum isolates, 68(100\%) were susceptible to ciprofoloxacin, 60(88\%) were susceptible to amikacin, 52(76\%) were susceptible to rifampin and $45(66 \%)$ were susceptible to gentamicin, while 20 S.entreitidis isolate, $18(90 \%)$ were susceptible to ciprofloxacin, and 16(80\%) were susceptible to amikacin. These findings are also very close to many studies $(15,27,28$ and 29). In particular the long term use of insufficient doses is regarded as one of the major factor responsible for development of antibiotic resistance (30). 


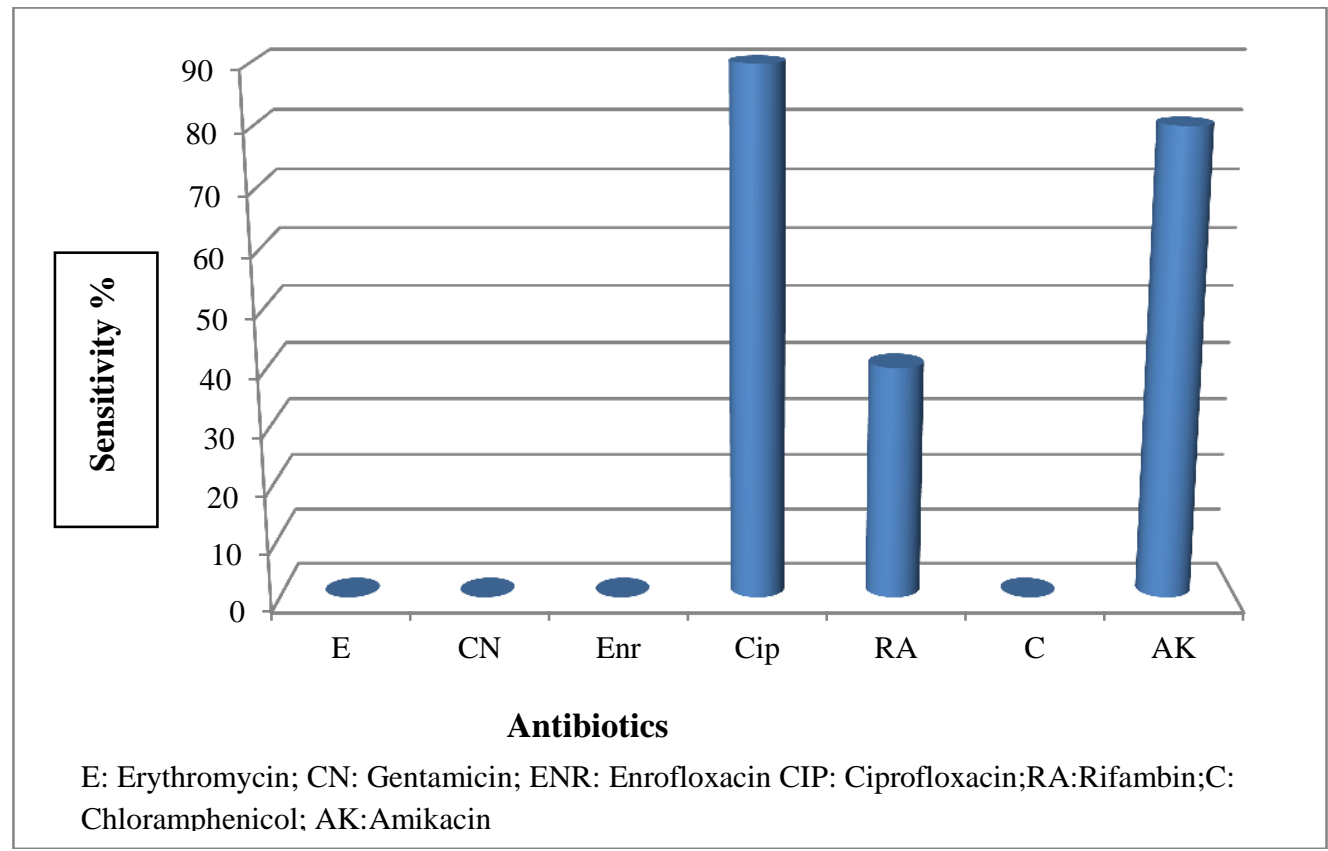

Figure (3): Sensitivity rate of S.entreitidis to different antibiotics.

\section{Conclusion}

In this study we conclude that rate of Bacillary white diarrhea infection in young chicks was high. S.pullorum was the predominant isolate. This study revealed that our isolates showed good sensitivity to most antimicrobials agents tested. The increasing prevalence of erythromycin, enrofloxacin and chloramphenicol resistance associated with reduced susceptibility to ciprofloxacin suggested that ciprofloxacin treatment may not be effective for serious Salmonella infection.

\section{Acknowledgements}

I am extremely thankful to the College of Veterinary medicine, Al-Qasim Green University, Dr.Sulake Fadhil and specialized pharmacist Ruaa Fadhil Abbas for providing all the needed facilities, which are essential for successful completion of the present work.

\section{References}

[1]. Barrow P.A. \&Freitasneto O.C. Pullorum disease and fowl typhoid - new thoughts on old diseases: areview. Avian Pathol., 2011; 40(1), 1-13.

[2]. Habrun, B. and M. Mitak. Monitoring for faecalSalmonella spp. in poultry. (2003). Croatian Veterinary Institute, Poultry Centre. Hrvatska, Zagreb, Croatia, pp: 161-163.

[3]. Calenge F, Kaiser P, Vignal A, Beaumont C. Genetic control of resistance to Salmonellosis and to Salmonella carrier-state in fowl:a Review. Genetics Selection Evolution, 2010; 42: 11

[4]. Izumiya H, Terajima J, Yamamoto S, Ohnishi M, Watanabe H, Kai A.Genomic Analysis of Salmonella entericaSerovarTyphimurium Definitive Phage Type104.Emerg.Infect. Dis. 2013; 19(5).

[5]. Priyantha MAR. Vaccination to control fowl typhoid in commercial layers, Sri Lanka. Sri Lanka J. Anim. Sci.2009; 1261469976.

[6]. Richardson E.J., Limaye B., Inamdar H., Datta A., Manjari K.S., Pullinger G.D., Thomson N.R., Joshi R.R., Watson M., Stevens M.P. Genome sequences of Salmonella entericaserovartyphimurium, Choleraesuis, Dublin, and Gallinarum Strains of well-defined virulence in food-producing animals.J. Bacteriol.,2011; 193(12), 3162-3163.

[7]. Quinne PJ, Carter ME, Markey B, Carter GR. Clinical Veterinary Microbiology Book. (1994). Wolfe Publishing, London.

[8]. Selvam, A., Gunaseelan, S.K. Kumar and M. Sekar. Assessment of carrier status of Salmonella pullorumand gallinaruminfection in health flocks. Tamilnadu J. Vet. Ani. Sci., 2010; 6: 99-101.

[9]. Snoeyenbos, G. H., Pullorum disease. Pages 73-86 in: Diseases of Poultry. 9th ed. B. W. Calnek, H. J. Barnes, C.W. Beard, W. M. Reid, and H. W. Yoder, (1991). Jr., ed. Iowa State University Press, Ames, IA.

[10]. Stephen AE, Peace OA, Wakili TA. Antibiograms of salmonella isolates from poultry farms in Ovia North East local government area,Edo State, Nigeria. Agricul. Biol.J. North Am.,2010; 1(6): 1287-1290

[11]. Al-Ferdous,T.. Lutful, K.S. Mansurul, A.A. and Mahmud,H.K. Identification and Antimicrobial Susceptibility of Salmonella species Isolated from Washing and Rinsed Water of Broilers in Pluck Shops. Int. J. Anim. Veter. Adv., 2013; 5(1): 1-8.

[12]. Crump JA, Medalla FM, Joyce KW, Krueger AL, Hoekstra RM, Whichard,J.M.Antimicrobial resistance among invasive nontyphoidalSalmonella enterica isolates inthe United States: National Antimicrobial Resistance Monitoring System, 1996 to 2007. Antimicrob AgentsChemother. 2011; 55(3):1148-54.

[13]. Hakanen A, Kotilainen P, Huovinen P, Helenius H, Siitonen A. Reduced fluoroquinolone susceptibility in Salmonella entericaserotypes in travelers returning from Southeast Asia.Emerg. Infect. Dis., 2001; 7: 996-1003.

[14]. Kariuki S, Revathi G, Kariuki N, Kiiru J, Nwituria J, Muyodi J, Githinji JW. Invasive multidrug-resistant nontyphodal Salmonella in Africa:Zoonotic or anthroponotic transmission.J. Med. Microbiol., 2006b; 55: 585-591. 
[15]. Solghan SM, Dumas NB, Root TP, Quinlan TM, Armstrong LR, Spina NL.Multidrug-resistant nontyphoidalSalmonella in New York State's foodborne diseases active surveillance network counties. Foodborne Pathog. Dis., 2010; 7(2):167.

[16]. Cheesbrough, M. District laboratory practice in tropical countries, (2002). E.C.B.S edition Combridge University Press 2:97-182

[17]. Perilla, M. J. Manual for the laboratory identification and antimicrobial testing of bacterial pathogens of public health importance in the developing world. (2003). World health organization. Atlanta Georges U.S.A Pp. 133 - 284.

[18]. Clinical and Laboratory Standards Institute (CLSI, formerly NCCLS):Performance standards for antimicrobial susceptibility testing, (2010): Seventeenth informational supplement.

[19]. Holt P.S. \&Chaubal L.H. Detection of motility and putative synthesis of flagellar proteins in Salmonella pullorumcultures. J. Clin. Microbiol., 1997;35, 1016-1020.

[20]. Kang M.S., Kwon Y.K., Jung B.Y., Kim A., Lee K.M., An B.K., Song E.A., Kwon J.H. \& Chung G.S. Differential identification of Salmonella entericasubspentericaserovarGallinarumbiovarsGallinarum and Pullorum based on polymorphic regions of glgC and speC genes. Vet. Microbiol., 2011:147, (1-2), 181-185.

[21]. Muktaruzzaman, M., M.G. Haider, A.K.M. Ahmed, K.J. Alam, M.M. Rahman. Validation and refinement of Salmonella pullorum(SP) colored antigen for diagnosis of Salmonella infections in the field. Int. J. Poul. Sci., 2010; 9: 801-808.

[22]. Lee, Y.J., K.S. Kim, Y.K. Kwon, M.S. Kang, I.P. Mo, J.H. Kim and R.B. Tak. Prevalent characteristics of fowl typhoid in Korea. J. Vet. Clin., 2003; 20: 155-158.

[23]. Medeiros, M.A.N. Prevalence de Salmonella spp. e Resistencia antimicrobial dose isolators'emCaracas de fringecongealed no Viejo. Brazil, 2004 a 2006. In: SeminalInternacional de SalmonelosesAviaries, (2011).

[24]. Parveen S, Taabodi M, Schwarz JG, Oscar TP, Harter-Dennis J, White DG. Prevalence and antimicrobial resistance of Salmonella recovered from processed poultry.J. Food Prot, 2007; 70: 2466-2472.

[25]. Sjölund-Karlsson M, Howie R, Rickert R, Krueger A, Tran TT, Zhao S. Plasmid-mediated quinolone resistance among nonTyphiSalmonella enterica isolates, USA.Emerg. Infect. Dis. 2010; 16: 1789-1791.

[26]. Whichard JM, Medalla F, Hoekstra RM, McDermott PF, Joyce K, Chiller T.Evaluation of antimicrobial resistance phenotypes for predicting multidrug-resistant Salmonellarecovered from retail meats and humans in the United States.J. Food Prot., 2010; 73(3):445-51.

[27]. Fashae K, Ogunsola F, Aarestrup MF, Hendriksen SR. Antimicrobial susceptibility and serovars of Salmonella from chickens and humans in Ibadan, Nigeria.J. Infect. Dev. Ctries., 2010; 4(8): 484-494.

[28]. Kabir, S.M.L. Avian colibacillosis and salmonellosis: A closer look at epidemiology, pathogenesis, diagnosis, control and public health concerns.Int. J. Environ. Res. Public Health, 2010; 7: 89-114.

[29]. Shah, A.H. and N.A. Korejo. Antimicrobial resistance profile of Salmonella serovars isolated from chicken meat. J. Vet. Anim. Sci., 2012; 2: 40-46.

[30]. Jafar A. A study on transfer of antibiotic resistance plasmids between Salmonella enteritidis and Escherichia coli K12. Int. J. Agr.: research and review, 2012; 2 (6), 862-866. 